\section{FUTUROS SOCIALES EN TIEMPOS DE CRISIS}

\author{
Ramón Ramos Torre \\ Universidad Complutense de Madrid \\ rrt@cps.ucm.es \\ ORCID iD: http://orcid.org/0000-0003-4691-6308
}

Cómo citar este artículo/Citation: Ramos Torre, R. (2017). Futuros sociales en tiempos de crisis. Arbor, 193 (784): a378. doi: http://dx.doi.org/10.3989/arbor.2017.784n2001

\section{SOCIAL FUTURES IN CRISIS TIMES}

Copyright: (C) 2017 CSIC. Este es un artículo de acceso abierto distribuido bajo los términos de la licencia Creative Commons Attribution (CC BY) España 3.0.

Recibido: 17 junio 2014. Aceptado: 9 mayo 2016

RESUMEN: En este artículo se reconstruye selectivamente la sociología del futuro de los últimos cincuenta años para rescatar algunos de sus elementos y construir una analítica y una problemática del futuro en tiempos de crisis. En su marco se reconstruye la evidencia empírica sobre el futuro social proporcionada por nueve grupos de discusión realizados en el marco de una investigación sociológica sobre el riesgo, la incertidumbre y la vulnerabilidad.

PALABRAS CLAVE: Sociología del futuro; sociología del tiempo; crisis.
ABSTRACT: This article reconstructs the sociology of the future of the last fifty years in order to rescue some of its elements and build a framework in which to analyze the problem of the social construction of the future in times of crisis. The article then reconstructs the empirical evidence on the social future provided by nine focus groups carried out in the context of sociological research into risk, uncertainty and vulnerability in Spain.

KEYWORDS: Sociology of the future; sociology of time; crisis. 


\section{INTRODUCCIÓN}

Las variaciones en los discursos del riesgo se relacionan siempre con variaciones a veces muy complejas en las maneras de concebir y vivir la incertidumbre y el futuro. Sobre esto existe un consenso amplio. Aproximaciones tan distintas como las de Beck (2008), Douglas (1994), Fischhoff y Kadvany (2013), O'Malley (2004), Luhmann (1992) o Lyng (2005) coinciden plenamente en esta relación a tres entre riesgo, incertidumbre y futuro, entendiendo que el riesgo es una forma social de relacionarse con el futuro (o con los futuros) incierto(s): los calcula, los escruta, los imagina, los barrunta, los desea o los teme, los pretende conformar, los evalúa comparándolos con futuros pasados, los intenta prever, prevenir, compensar, precaver, etc., etc.

Lo que aquí se presenta se enmarca en una investigación sobre el riesgo y la incertidumbre que, consecuentemente, se ha abierto al estudio del futuro. En efecto, las propuestas que se van a hacer sobre la semántica social del futuro surgen de una investigación sociológica ya realizada que, bajo el título general de Riesgo, incertidumbre y vulnerabilidad en España ${ }^{1}$, rastrea los discursos o retazos discursivos sobre esos campos de experiencia de distintas categorías de la población española considerados estratégicos².

El objetivo central de la investigación no era ni la crisis ni la manera de enfrentar el futuro, pero el desarrollo de los grupos de discusión hizo emerger esos dos temas de forma recurrente y protagonista. En efecto, en el trascurso de las discusiones, y actuando como escenario permanente de las prácticas discursivas que iban surgiendo, dominaba la conciencia de estar viviendo una CRISIS (en grandes mayúsculas) sin precedentes, totalmente inesperada y percibida como social y personalmente catastrófica. Y así la crisis acaba aportando el marco para el discurso como la experiencia traumática de todos, cuyo protagonismo central en el campo del hacer y el decir nadie pone en duda. $Y$ es en el marco de esa crisis y su específica semántica ${ }^{3}$ donde emergen los discursos sobre el futuro. Consecuentemente, el futuro no se enfrenta en sí, como eventual objeto de reflexión o motivo para dar cuenta de certezas, temores y esperanzas personales o colectivas, sino siempre y de forma obsesiva en el marco que le proporciona la experiencia de la crisis. Es así un futuro crítico, lo que lo dramatiza aún más y permite someter a un contraste agudo, como se verá, los tópicos que la modernidad ha ido acumulando sobre él. La semántica social del futuro se configura al chocar con ellos, sopesarlos, matizar o problematizar radicalmente su plausibilidad: al futuro sosegado del mundo previsible del estado del bienestar y la sociedad de aseguración de riesgos, se contrapone el futuro crítico, inseguro, próximo a lo que los psicólogos denominan "ansiedad de futuro" (Zalesky, 2005) o futuro ansioso.

En lo que sigue, haré (1) un recorrido selectivo por la sociología del futuro tal como se ha ido configurando en los últimos cincuenta años para, en el marco de sus aportaciones, (2) presentar una propuesta sobre la analítica y la problemática del futuro que posibilite, en la última sección (3), mostrar el repertorio de sentido sobre el futuro que aparece en los discursos sociales. Unas sucintas conclusiones cerrarán el trabajo.

\section{SOBRE LOS ESTUDIOS SOCIALES (O SOCIOLOGÍA) DEL FUTURO}

En términos generales, la conceptuación del futuro ha cambiado poco desde las reflexiones de Aristóteles sobre los futuros contingentes en Perí hermeneias (Valdés Villanueva, 2012) o las de Agustín de Hipona sobre el presente de las cosas futuras en Las Confesiones (San Agustín, libro XI, § 26 y ss.).

En las ciencias sociales, los intentos de construir una sociología del futuro tuvieron su primera época de gloria en Francia y USA en los años '70 del siglo $X X$. Los conocidos trabajos de Bertrand de Jouvenel (1966) sobre el arte de la conjetura en la política y de Wendell Bell ${ }^{4}$ son exponentes de esa coyuntura que generó muchas publicaciones sobre el tema -algunas de gran impacto social, como las del Club de Roma de los años '70- y configuró un cierto movimiento de escuela con ramificaciones en USA y Europa ${ }^{5}$. El concepto implícito de futuro del que se servía esa ciencia social (sociología, ciencia política o futurología sin más) era más bien simple o de sentido común ${ }^{6}$. Se suponía que el futuro se encontraba recogido en imágenes sustentadas socialmente y que en ellas el analista podía distinguir netamente lo posible, lo probable y lo deseable. El objetivo de la indagación no era otro que fijar las tendencias del cambio social y eventualmente guiarlo de forma que solo se realizaran las posibilidades favorables, acordes con los valores de la sociedad norteamericana contemporánea. No se caía en la ingenuidad de creer que el futuro fuera en bloque elegible y construible de manera intencional y exitosa, pues se reconocía que la acción que debería realizarlo era susceptible de reflexividad y se desplegaba en un medio complejo. La reflexividad (y las mertonianas profecías que se destruyen a sí mismas) y la complejidad (entendida como pues- 
ta en conexión de elementos muy dispares de un mismo sistema) unidas hacían que el futuro pudiera sorprendernos y contrariar nuestras expectativas y deseos. En cualquier caso, esta sociología del futuro (o futurología) era una ciencia optimista, volcada en calcular el porvenir y garantizar un futuro acorde con nuestros valores de libertad y bienestar. Su mensaje era que el futuro estaba en nuestras manos si éramos lo suficientemente prudentes como para abordarlo, calcularlo y elegirlo. Su orientación claramente pragmática era su rasgo predominante.

Otra línea, extendida en las revistas científicas de sociología pero sobre todo en las de psicología social o psicología (a-social) sin más, exploraba y explora lo que se denominó de forma variada orientaciones, actitudes, horizontes o perspectivas de futuro (o temporales) para analizar sus relaciones con los problemas recurrentes de lo que, en el lenguaje de la época, se llamaban desviaciones o problemas sociales. Estos podían ser muy variados: marginación social, pobreza, drogadicción, conductas de riesgo, fracaso escolar, depresión, suicidio, enfermedades mentales, llegando incluso a las desigualdades y discriminaciones ligadas a las diferencias étnicas o de clase. La idea de fondo era que una configuración inadecuada de las orientaciones, horizontes o perspectivas de futuro iba de la mano de (o por lo menos mostraba fuertes correlaciones estadísticas con) una situación de desviación/ marginación social. La relación causal no estaba clara, aunque se tendía a dar a entender que una conformación defectuosa de la perspectiva de futuro (escasa profundidad, desestructuración, fatalismo, deseo de una gratificación inmediata, ausencia de planes, etc.) arrastraba a un destino de insatisfacción vital, marginación social o destierro a los escalones ínfimos de la estratificación social. Poco teórica, nada literaria y muy basada en la investigación empírica preferentemente cuantitativa, la bibliografía sobre el tema es ingente. Arranca de los años 50, con los conocidos trabajos de Leshan (1952) sobre las orientaciones temporales de las clases sociales, se prolonga en las tres décadas posteriores (véanse Kastembaum, 1961; Nuttin, 1985 y Trommsdorf y Lamm, 1975), Ilegando hasta la actualidad con mayores sofisticaciones metodológicas $^{7}$-por ejemplo en la extensa obra de Zimbardo y sus múltiples seguidores (véase Zimbardo y Boyd, 2009).

De un espesor sociológico mayor, los escritos de Mercure (1983) a principios de los '80 pretendieron dar cuenta de las distintas configuraciones sociales del futuro. El autor diferencia cinco variantes del futu- ro: fatalista, previsor, continuista, etapista y posibilista. Son tipos construidos a partir de una investigación cualitativa realizada en Québec en la que se centró la atención en los planes de vida y la perspectiva sobre el porvenir de hombres y mujeres en distintas posiciones en la estructura social. Aunque no se resolvía en términos de un esquema causal unidireccional, Mercure, a diferencia de los psicólogos antes reseñados, destacaba que la situación en la estructura social de los sujetos entrevistados era clave para comprender su imagen del futuro.

En esa línea de investigación hay que situar trabajos publicados en los últimos diez años en el marco de lo que se puede denominar estudios sociales de la incertidumbre y el futuro ${ }^{8}$. Es propio de estas investigaciones la utilización de técnicas cualitativas de indagación (entrevistas en profundidad, focus groups), una cierta, pero limitada, tensión teórica -sobre todo en relación al problema genérico de la (pos)modernidad y la descomposición del tiempo- y un interés directo en perfilar las distintas estrategias de concebir y vivir el futuro de la categoría social que analizan. Si el asunto interesa no es, como en el caso de los trabajos de orientación psicológica, para generar un saber que permita diagnosticar (y luchar contra) las desviaciones socio-personales, sino para dar cuenta de las distintas conformaciones de las identidades colectivas: el tiempo y especialmente la idea del futuro es uno de sus pilares fundamentales.

Los trabajos hasta ahora reseñados son de marcada orientación empírica. Están pues ligados a los instrumentos de observación de psicólogos (sociales o no) y sociólogos y a sus técnicas de explotación (mayoritariamente cuantitativas, pero también cualitativas) de los datos que producen. El resultado es la acumulación de datos-informaciones sobre categorías sociales circunscritas, la producción de conceptos de corto alcance o ad hoc, la sumisión de la reflexión teórica a su operativización tecno-metodológica, un muestrario variado sin ensamblar de tipologías de futuros constituidos.

Pero no agotan el campo de los estudios sociales sobre el futuro. Hay que considerar también distintos ramales de la ciencia social (sociología, ciencia política, antropología, geografía, pero también filosofía social y política) de los últimos 20 años en los que, ya sea en razón de la problemática de la posmodernidad, ya sea al hilo de la revolución de las tecnologías de la información y el conocimiento, ya sea de la mano de algunas tendencias emergentes del cambio social ligadas a la aceleración, se ha acabado desem- 
bocando en el debate sobre el tiempo y, en consecuencia, sobre el futuro. Sintetizando aproximaciones tan dispares como las de Jameson (1995 y 2003), Bauman (2000 y 2007) y Lipovetsky (1986 y 1990), o las de Castells (1997) y Eriksen (2001), o las de Harmut Rosa y Scheuerman (2009) -o entre nosotros Beriain (2008) e Innerarity (2009)-, podemos decir que lo propio de esta ciencia social del futuro es el diagnóstico que anuncia su desaparición, diagnóstico en el que, siguiendo hipótesis y analizando fenómenos sociales muy dispares, coinciden -ya sea que lo consideren un destino manifiesto, ya sea que lo celebren, ya que lo lamenten y propongan una alternativa ${ }^{9}$. En todos estos casos, lo que se acuerda es que el futuro tal como lo concibió la modernidad, o tal como era cuando las TICs todavía no nos habían revolucionado, generando la sociedad en red, o tal como se esperaba cuando el ritmo de la vida social era más sosegado, ese futuro pasado propio de la primera modernidad o de la modernidad plena ha desaparecido. Lo que emerge es su ausencia o su achicamiento en razón del privilegio de lo instantáneo o de un presente que todo lo atrapa y no lo deja nacer. La sociología del futuro es aquí una sociología del ocaso y la desaparición; una sociología de la orfandad que asegura que nos hemos quedado sin él ${ }^{10}$.

Por fuera de esta orientación de la macro-sociología, hay otras dos aproximaciones que completan y cierran el recorrido: las de Niklas Luhmann y Barbara Adam; son las más cargadas de teoría, aunque ciertamente con orientaciones muy diferentes.

El interés de Luhmann por situar el problema del tiempo en el marco de la sociología es acusado a lo largo de toda su obra. Su interés por el futuro se plasmó en un trabajo de 1976 muy influyente, traducido en Ramos Torre (1992). En él, Luhmann, acogiéndose a una tradición que viene de Agustín de Hipona y llega a la ciencia social del siglo XX con Mead y Schutz, concibe el futuro como un horizonte del tiempo que ha de ser conceptuado en el marco de las iteraciones (futuro presente, presente futuro, pasado futuro, etc.) ya exploradas en las Confesiones agustinianas. Si los modernos sistemas sociales diferenciados han evolucionado hacia una temporalización de la realidad, esta se ha materializado en una creciente futurización ${ }^{11}$. Esta futurización plantea problemas que se han pretendido resolver siguiendo dos estrategias tendentes a la colonización del futuro incierto: son las estrategias de desfuturización propias de la tecnología y la utopía. Ambas acuerdan que el futuro no puede empezar, pero dan certezas para conformarlo o esperarlo. En consecuencia, las crisis de la modernidad son crisis de sus futurizaciones o, de forma más concreta, de sus estrategias de desfuturización o colonización.

Por su parte, Barbara Adam, en una reciente publicación en colaboración con Groves (Adam y Groves 2007), hace una aproximación sistemática al problema del futuro en la sociedad contemporánea. La idea crítica fundamental es que la historia del futuro que arranca de los esfuerzos de los chamanes y los profetas por conseguir certeza desembocó en los dos últimos siglos en la emergencia de un futuro abstracto, abierto y vacío, susceptible a su vez de ser administrado por medio de técnicas de previsión y proyección. Ese futuro, según argumentan, no está ya a la altura de los tiempos y de los problemas a que nos toca afrontar en este siglo que comienza, dominado por la amenaza ecológica y la desmesura de la colonización tecnológica (potencialmente catastrófica) del planeta. Es preciso pasar a concebir y configurar un futuro latente y producido -que está ya allí, con independencia de nuestros planes y previsiones, aunque sea en gran parte la consecuencia no-intencional de nuestro obrar- que rompa la vieja divisoria entre los facta y los futura, es decir, entre aquello que está hecho y es independiente de nuestra conciencia, por un lado, y lo que solo constituye un dato de la conciencia, por el otro. Concebir el futuro desde la óptica de lo factual es el núcleo de la propuesta de Adam para afrontar estos tiempos de complejidad y crisis ecológica.

Hasta aquí la presentación comprimida de la sociología del futuro de los últimos 50 años. Esta tradición deja un legado nada desdeñable. Por un lado, en muchas de sus variantes, se ha construido a partir de la investigación empírica, rescatando el problema del tiempo del puro debate de la logomaquia o las intuiciones poéticas. Por otro lado, rastreando esa bibliografía se puede conseguir un enriquecimiento notable del marco analítico de las indagaciones sobre el futuro: conceptos más afinados y complejos; articulaciones más ricas entre el futuro, el presente y el pasado; tipologías del futuro analíticamente explícitas y teóricamente fundamentadas. Además, todos esos trabajos han mostrado que la otra cara de una modernidad que temporaliza y futuriza la realidad es la problematicidad del tiempo y especialmente de un futuro al que se asigna papel tan preponderante. Por último, es evidente que esos trabajos están tensados por la relevancia pragmática del tema que abordan. Ya sea para establecer terapias sociales, ya para celebrar los nuevos espacios de la experiencia, ya para criticar la destrucción de los horizontes temporales y optar, 
al modo de Innerarity (2009, p. 133), por una nueva "crono-política", en todos los casos, el problema del tiempo/futuro se convierte en un problema de la acción, un problema social, un problema político.

\section{ANALÍTICA Y PROBLEMÁTICA DEL FUTURO SOCIAL}

Entiendo por analítica del futuro un conjunto trabado de conceptos que nos permite abordarlo, diseccionarlo, mostrar sus determinaciones fundamentales y eventualmente dar razón de sus cambiantes conformaciones. Entiendo por problemática del futuro el conjunto de problemas que la conformación del futuro presenta en una coyuntura socio-histórica. Lo que en este caso se problematiza es una conformación tópica de la semántica y la pragmática del futuro. Esto hace que lo que se daba por cierto y seguro deje de considerarse así.

La analítica y la problemática del futuro se han de configurar tomando en consideración la tradición de saberes (de especialistas y legos) sobre el futuro antes reconstruida. Es en el marco de esa tradición donde podemos fijar cómo hemos de pensarlo y qué es lo que, de los tópicos modernos dominantes, nos resulta incómodo, debatible o abierto.

En el proceso de fijación de una analítica del futuro los hitos fundamentales son: a) la aclaración de las iteraciones del futuro, b) el complejo conceptual que se arracima en lo que se suele denominar perspectivas de futuro y c) lo que pasaré a presentar como dimensiones del futuro -muy relacionado con lo que se fija en b). Haré una rápida incursión por todos ellos.

El modelo para concebir el tiempo en términos de iteraciones temporales lo proporciona Agustín de Hipona en el libro XI de las Confesiones. Fue recogido en la filosofía-teología medieval y rescatado para la sociología del tiempo por Luhmann (1976); posteriormente Adam y Groves (2007) lo consolidan ${ }^{12}$. En sustancia propone que la distinción usual entre el pasado y el futuro -los dos horizontes del presente cuyo concurso o diferencia configura el tiempo- puede llevar a combinaciones temporales tan inusitadas como analíticamente fértiles. Esas combinaciones repiten y entrelazan los tres conceptos temporales fundamentales, es decir, el presente, el pasado y el futuro.

En el contexto actual, se tomarán en consideración las posibilidades abiertas por tres iteraciones: el futuro presente, el presente futuro y el pasado futuro. Subrayemos que, en todas ellas, el orden de los términos sí altera el producto. Y es así porque, en todos los casos, el término que aparece en primer lugar cumple el papel de sustantivo, mientras el segundo término es un adjetivo que lo cualifica ${ }^{13}$. Por lo tanto, la diferencia entre las expresiones futuro presente y presente futuro radica en que en el primer caso el futuro es el sustantivo cualificado por ser presente, mientras que, en el segundo, el presente es el sustantivo que resulta cualificado por ser futuro. Unas breves indicaciones adicionales bastarán para fijar lo que se entiende propiamente en cada caso.

Se entiende por futuro presente la idea o imagen que se tiene en el presente de lo que pueda ocurrir en el futuro. El futuro es siempre un horizonte del presente y sólo como tal se puede idear y vivir. San Agustín (Confesiones, Libro XI, § 26) insistía en esto: no hay un futuro, sino el futuro de las cosas presentes, es decir, de ciertos estados actuales de la conciencia que denominamos espera. Cada presente tiene sus horizontes de futuro. Es obvio que esos futuros presentes son múltiples y enfrentados (los futures contested de Brown, Rappert y Webster, 2000), pues muchas son las posibilidades de futuro que coexisten en un presente $y$, en consecuencia, muchos los horizontes de futuro que contrastamos, sopesamos, desechamos, tememos o apetecemos.

A su vez, los futuros presentes se diferencian del presente futuro porque este hace referencia a lo que será lo que ahora consideramos futuro cuando realmente ocurra y se haga presencia. Cuando conjeturamos el futuro siempre se juega con esta relación entre el plano de lo que ahora podemos idear o barruntar como tal y el plano de cómo se conformará cuando se actualice eso que ahora solo podemos pensar como (im)posible. Evidentemente, el discurso del futuro dramatiza siempre las relaciones entre los futuros presentes y el definitivo, concreto e ineluctable presente futuro que se esconde por detrás de aquellos.

Por su parte, se entiende por futuros pasados los futuros que se idearon y tomaron en consideración en el pasado y que, entonces, fueron relevantes para reducir la incertidumbre de base del tiempo por venir. Por medio de la memoria podemos recordarlos y contrastar las esperanzas o temores de entonces con lo que finalmente ocurrió y pasó a configurar el presente en el que recordamos. Por reducirlo a ejemplos expresivos: ¿qué fue de las predicciones del Club de Roma?; ¿o del futuro de la sociedad industrial como sociedad pos-industrial?; ¿o de los pronósticos sobre la sociedad del ocio o de un mundo de complacidos humanos que observarían cómo trabajarían para ellos millones de autómatas sin alma, pero dóciles? Es evidente que una sociología reflexiva debería atender a los futuros 
pasados que sus expertos han vaticinado y aprender a lidiar el problema correoso del tiempo tomando eso en seria consideración.

Las iteraciones temporales nos sirven para analizar las múltiples formas en las que el futuro se dice. En ese marco, se consigue una mayor riqueza analítica si, de acuerdo con la línea teórica Agustín-Mead-Luhmann, concebimos el futuro como un horizonte del presente ${ }^{14}$. Es aquí de ayuda la ingente producción que en psicología (social o no) y sociología se ha ido acumulando sobre lo que se tiende a denominar las perspectivas temporales y, específicamente, la perspectiva del futuro. Se trata del segundo punto del recorrido por la analítica del futuro antes anunciado.

Ya antes se apuntaba que el tema no es pacífico ni siquiera en el campo terminológico. Lo que la tradición de los future studies denomina imágenes del futuro, Leshan en los años 50' y Tommsdorf en los 70' orientaciones temporales, se tiende a denominar desde los trabajos de Wallace y Kastenbaum perspectiva temporal (de futuro), lo que ha quedado consagrado tras los trabajos de Zimbardo y su propuesta de un muy ambicioso (y muy utilizado en la investigación empírica) Inventario de Perspectiva Temporal de Zimbardo (ZTPI, en sus siglas en inglés) (Zimbardo y Boyd, 2009). Una cierta disidencia en este campo la protagoniza Joseph Nuttin (1985) que en su influyente trabajo de los años 80 propuso ordenar conceptualmente este campo distinguiendo entre las orientaciones, las actitudes y las perspectivas de futuro (o temporales sin más). Aunque está claro que estas distinciones no se han asentado y los trabajos de referencia utilizan el término perspectiva en el que recoge y une lo que Nuttin diferencia, es posible fijar la semántica de la perspectiva de futuro de la manera que sigue.

Si el futuro es una perspectiva, se trata entonces de un horizonte que se contempla desde un determinado punto de observación (siempre situado en el presente). Se supone así que lo contemplado depende del punto de vista, pero también que puede ser algo en sí mismo (futuro latente de Adam) con independencia de quién y cómo se observa, dejando así suelta la sensibilidad para considerar los aspectos factuales de los futura. Siguiendo básicamente a Nuttin (1985), el horizonte de escenarios, entes y acontecimientos contemplados puede tener mayor o menor profundidad o extensión, ser más o menos denso en razón de la cantidad de elementos que considera, mostrar una mayor o menor estructuración (conexión, transitividad, narratividad etc.) entre lo que contiene, transmitir una mayor o menor viveza o realismo y eventualmen- te diferir en su precisión temporal (orden temporal y cronología). Todo esto permite distinguir diferentes perspectivas temporales o diferencias entre categorías sociales en función de sus variadas perspectivas. Estas diferirán en razón de su extensión, densidad, estructuración, viveza y precisión temporal.

Obviamente, esto no agota lo mentado al hablar de las perspectivas temporales. Al lado de las determinaciones ya especificadas, las perspectivas contienen diferentes dimensiones. De acuerdo con los trabajos de referencia, podemos distinguir al menos cuatro básicas. Por un lado, las dimensiones cognitivas que hacen referencia a contemplar, saber, conjeturar, calcular, imaginar, suponer, etc., cosas, escenarios, personajes y acontecimientos situados en el futuro. Por otro, la perspectiva más propiamente práctica o ligada a la acción (en los trabajos de psicología se suele denominar motivacional) en la que se contrasta, en términos de factibilidad, lo que se puede/debe hacer vs lo que hay que sufrir -y sus eventuales círculos paradójicos ${ }^{15}$-. Además hay, evidentemente, una dimensión valorativa en la que se resuelve el carácter favorable/desfavorable de las contingencias futuras. Por último, pero con relaciones muy intrincadas con las tres anteriores, hay que destacar una dimensión emocional o catéctica que se materializa en temores, confianzas, deseos, esperanzas, etc. En consecuencia, a la hora de dar cuenta de una perspectiva de futuro no basta tan solo considerar su profundidad, densidad, estructuración, viveza y temporalización, sino que también hay que atender a las dimensiones cognitivas, prácticas, valorativas y emocionales con las que se procesa ese horizonte.

Fijada así, esquemáticamente, la analítica del futuro, se puede entrar en lo antes anunciado como problemática del futuro. Aquí se puede ir más deprisa. Si, según lo antes propuesto, la problemática del futuro no es otra cosa que la problematización que en una determinada coyuntura se hace de la visión tópica dominante, entonces podemos colegir que las variantes actuales de la problematización del futuro -recuérdese: en tiempos de una fuerte autoconciencia de CRISIS- harán referencia a lo que han sido sus rasgos dominantes (aunque fluctuantes, polemizados, desvanecidos a veces, etc.) en la modernidad triunfante. Atendiendo a los análisis de Koselleck, Luhmann y Adam se pueden fijar ciertos rasgos como sus determinaciones fundamentales. Son la novedad, la apertura, la colonización tecno-utópica y la mejora o progreso.

El futuro como novedad. La emergencia de novedades como expresión más propia del futuro es una idea típicamente moderna que enfatiza la asimetría 
entre el espacio de la experiencia y el horizonte de la expectativa (Koselleck, 1985). Si la modernidad supone la emergencia incesante y legítima de novedades que no tienen precedente -y esto proponía la definición canónica del inventor del término, Baudelaire-, entonces su futuro lo concibe como emergencia de novedades que pueden o no llegar a ser imaginadas, pero que chocarán con las cosas a las que estamos acostumbrados. Supone, pues, ir más allá de lo familiar, remozándolo o arrinconándolo. Lo que no cabe pensar es un futuro que sea la cansina repetición de lo mismo, el cierre del círculo pitagórico que une principio y final.

Apertura del futuro. El futuro de los modernos es abierto. Que esté abierto no se puede identificar con el tópico de la incertidumbre y la eventual sorpresa. Indica más bien la conformabilidad del futuro por parte de la acción, su factibilidad, lo que Rescher (1998) Ilama su tractability (manejabilidad). Un futuro abierto es uno en relación al que podemos ahora -y eventualmente podremos mañana- hacer algo. No quiere decir que vaya a ser conformado según la intención (individual o colectiva), ya que para los modernos es clara la ironía de la acción y sus recurrentes consecuencias no-intencionales, externalidades, efectos colaterales o perversos. Con todo, las consecuencias no intencionales -incluso en su forma menos amable de consecuencias perversas- no hacen sino reafirmar el carácter abierto del mundo y, con él, del futuro. Los antiguos leían lo que se enfrentaba a la intención y eudiamonía de los humanos como destino o juego insensato de la fortuna; Boecio, a principios del siglo VI, ensayó el puente de sentido que permitía pasar del destino-fortuna a la Providencia de Dios; la modernidad, por el contrario, dio por descontado que todos esos infortunios mostraban simplemente lo que surgía de la acción humana o sus artefactos aunque no estuviera en sus intenciones.

Colonización tecno-utópica del futuro. Como muestran Adam y Groves (2007) en una reconstrucción paciente de sus variantes, todas las culturas-sociedades humanas se han enfrentado con la incertidumbre constitutiva del futuro y han intentado reducirla, colonizándolo. Colonización no significa abolición de la incertidumbre que le es propia, sino la apuesta por ampliar o adensar su "gozne" (Wittgestein 1988) de certeza ${ }^{16}$. Luhmann (1976) propone que la colonización del futuro (o desfuturización parcial) propia de la modernidad se encarna en la tecnología y la utopía. Ambas suponen un horizonte dotado de profundidad. La primera asegura la selección de algunos de los futuros presentes; la segunda, la ideación de un presente futuro cumplidor definitivo de las promesas emancipatorias. Tal vez la expresión más cumplida de la colonización técnica del futuro se encuentra en la constitución y desarrollo del estado social o estado del bienestar. Sus mejores analistas (Baldwin, 1992; Castel, 1997; Ewald, 1996) han mostrado que su aportación básica es la utilización de una tecnología de evaluación-gestión de riesgos sociales que genera seguridad y reduce la incertidumbre del futuro en aspectos fundamentales de la existencia (salud, vivienda, alimentación, reproducción, formación, etc.). Por su parte, la utopía anima la tensa espera de un presente futuro que acabará por llegar, en el que la humanidad acceda a la verdadera historia (Marx) o se libere de la historia, abriendo la "pequeña puerta por la que el Mesías podría penetrar" (Benjamin, 1940/2012, p. 318).

El futuro como mejora o progreso. Se trata de una de las ideas que, aunque con precedentes en la historia de occidente, sólo triunfa plenamente hasta convertirse en un tópico en la sociedad moderna (Nisbet, 1981). No se limita a suponer que el mundo es abierto y está abocado a novedades sin cuento, sino que además se orienta hacia mejoras continuas o discontinuas, que se pueden sumar y dan una orientación a la historia. Lo que cabe esperar -parezca o no claro y manifiesto- es siempre un más, una mejora, un paso adicional, la actualización de lo preferible -como diría Wendell Bell. Puede parecer que lo que ocurre en la actualidad lo desmiente; incluso se puede asegurar que la insociable sociabilidad y una naturaleza madrastra (Kant) lo dominan todo. Pero en la colmena humana siempre hay que esperar que de las acciones egoístas surjan consecuencias altruistas o que de la búsqueda del poder, la riqueza y el honor particulares surjan la libertad, el derecho y el bienestar común. El progreso y el bien se fundamentan -ya lo dijeron Leibniz, Mandeville, Vico y Smith- en el Principio Consecuencial (Ramos Torre, 2002b).

Si estas son las notas sobresalientes del futuro tópico o imaginario de las sociedades modernas, entonces la problematización del futuro no será otra cosa que la puesta en cuestión de su plausibilidad, es decir, el cuestionamiento (o la acumulación de anomalías difíciles de aceptar) de su despliegue de novedades sin precedentes, o de su apertura práctica o conformabilidad, o de la colonización tecno-utópica o de su encaminarse hacia mejoras y progresos. La información que brinda la investigación empírica debería aclarar en qué sentido o en qué medida ese futuro moderno está siendo problematizado. 


\section{FUTUROS SOCIALES EN TIEMPOS DE CRISIS: REPERTORIO DE SENTIDOS}

Lo anterior brinda el marco para adentrarse en el análisis de la evidencia empírica producida en la investigación antes referida. En esta sección fijaré un repertorio de sentidos a la mano que aparecen en las discusiones de los grupos. Entiendo por repertorio el conjunto o colección de las imágenes, ideas, expresiones, barruntos, intuiciones, etc. que surgen al hilo de las discusiones de los grupos. Son un repertorio de sentido a la mano porque fijan la colección de sentidos disponibles para actuar en el espacio social de la comunicación.

La que sigue es una muy primera exploración, limitada a fijar los retazos de sentido emergentes sin intención ninguna de reconstruir el discurso entero en el que se puedan integrar, ni de establecer el sistema de discursos existentes y asignarlos a distintas categorías sociales. Eso queda a la espera de trabajos ulteriores. Lo que ahora se pretende es rescatar retazos -o esbozos o piezas o astillas- de ese repertorio de sentido a la mano. Muestran los tópicos que salen en las discusiones y las animan.

Para presentarlos, opto por organizarlos a lo largo de ejes en los que cabe diferenciar dos posiciones extremas. Los retazos discursivos se ubican en uno $u$ otro extremo o en posiciones intermedias. En cualquier caso, en esos ejes se muestran los límites de la plausibilidad del viejo discurso tópico de la modernidad sobre el futuro, las variadas conformaciones de las perspectivas de futuro, sus dimensiones y el modo en que se articulan las iteraciones temporales.

El análisis del material de los nueve grupos de discusión induce a distinguir al menos seis ejes fundamentales en los que se ordenan los tópicos sobre el futuro. Paso a recorrerlos en sucesión, acompañando la descripción de algunos verbatim expresivos.

Eje 1 o de la dimensión práctica del futuro. En este eje se contrapone un futuro que se hace, tiene, consigue, produce o construye, es decir, un futuro que está abierto a la conformación por parte de un actoragente, contra un futuro que "hay", sucede, ocurre, pasa, "sale", es decir, un futuro que aparece como un conjunto de facta que se le vienen literalmente encima a un actor-paciente. Es congruente con estas dos conformaciones polares en el eje práctico la imagen de un futuro hacia el que se va o se avanza, un futuro que se explora, se contrapone a la imagen de un futuro que viene por sí mismo, se nos cae encima, se da conocer. Es una doble imagen del tiempo muy asen- tada en el lenguaje (Lakoff y Johnson, 1995, pp. 79 y ss.): el tiempo como aquello por lo que me desplazo (ego se mueve por un tiempo que está 'quieto') vs el tiempo como lo que se me viene encima (el tiempo se desplaza hacia un ego a la espera).

Expresiones del primer tipo son menos numerosas de lo que cabría esperar dados los tópicos meritocráticos dominantes. Aparecen nítidamente en las discusiones de dos categorías sociales: funcionarios y estudiantes. Se demanda lo que se hace para construir o formar el futuro, lo que presupone su factibilidad:

“¿Qué hace la gente por sí misma para la construcción de ese mañana? ¿Qué hacéis vosotros para la construcción de ese mañana?" (Funcionarios: GD1).

"Estamos estudiando y formando nuestro futuro, pues que dé sus frutos dentro de unos años" (Estudiante: GD3).

Frente a la imagen de un futuro que se hace, forma o construye, está la inversa del futuro que sale al encuentro de repente, sin que hagamos nada, que está, para gusto o disgusto, ya hecho y nos cae encima. Frente a él poco cuenta la capacidad de acción de un actor-agente; cuenta más bien la vieja diosa fortuna. Tal implícito informa la siguiente intervención de un trabajador industrial en la que se ponen en relación futuros pasados con un presente futuro que nos saldrá al encuentro:

"Siempre hemos sido un país de servicios... de repente, descubrimos la construcción.... Oye, todo el mundo nos apuntamos a la construcción. Los ayuntamientos los primeros.... Que han sido los primeros en meternos en el follón. Pues en vez de la construcción, saldrá otra cosa. Digo yo, que nos lleve a algo bueno. Porque sin esperanza, desde luego..." (Empleado fijo: GD7).

Ese futuro que sale no es el que se hace o construye; es un tiempo que viene y va sin que podamos hacer mucho para atraparlo; todo lo más, podemos acomodarnos a sus dictados, apuntarnos a él.

Eje 2 o de la certeza. En este eje se contrapone lo que se sabe, contempla, puede pensarse y hablar, frente a lo que no se ve, se ignora, no se piensa e incluso se silencia. Las metáforas fundamentales son visuales, destacando la contraposición luz/oscuridad. También emergen metáforas auditivas: aquello de lo que se habla y se escucha vs aquello que se silencia o no se quiere escuchar. Evidentemente, la experiencia y dramatización de la crisis, como situación personal o colectiva, va de la mano de lo oscuro (negritud), el silencio o el no querer escuchar. Además lo puramen- 
te cognitivo se mezcla con la expresión de la voluntad: no solo no se ve, sino que no se quiere ver; no solo no se habla, sino que no se quiere hablar. Algunas intervenciones permiten plasmarlo:

No querer ver. “¿El futuro? Jodido. Mantenerme y aguantar a ver lo que sale, no veo mucho más para allá. Futuro... no veo, me quedo donde estoy y el día a día. O sea, no veo... no quiero verlo [...] No quiero verlo. No quiero avanzar. No quiero. No quiero, porque no quiero ver. Mantenerme con lo que tengo. Punto" (Varones autónomos: GD6).

No querer hablar/oír. "En el fondo estamos hablando todo el rato y si te das cuenta, nadie quiere hablar del futuro. Estamos todos aquí atrincherados diciendo, mientras mañana salga el sol" (Varones autónomos: GD6).

Eje 3 o de la profundidad del futuro. Lo que cuenta aquí es la conformación del horizonte de futuro tal como se plasma en la perspectiva desde la que se contempla. La contraposición es, por un lado, la imagen de un horizonte largo, poblado de acontecimientos con una cierta viveza, eventualmente conectados entre sí y con cierta explicitación temporal y, por el otro, lo que es más bien barrunto de un horizonte corto, comprimido o inexistente que linda con un presente casi auto-contenido y auto-suficiente. Las metáforas son visuales, centradas en el contemplar, ver, incluso calcular algo que se contempla con nitidez. La experiencia de la crisis es la de la disminución o compresión del futuro. Sobre todo entre los que se saben indefensos o impotentes, para los que como mucho cabe hablar de un bifurcación de horizontes del futuro: el propio, muy estrecho; el de los hijos, más largo. Los fragmentos que explicitan estas posibilidades son frecuentes:

Compresión del horizonte hasta hacerlo desaparecer a favor de un presente sin fronteras externas, a modo de terapia frente a la frustración. "tienes que vivir el día a día porque no sabes lo que te va a pasar mañana" (Mujeres técnicas/profesionales: GD2).

"Es lo que decís vosotros, me preocupa el día a día, ahora mismo no piensas en el futuro casi, porque bastante tienes" (Varones autónomos: GD6).

"Hay que cambiar el chip, y el chip es vivir día a día. No crearte metas ni a favor ni en contra, porque si no, lo tienes jodido. Jodido porque te puedes coger depresiones de lo que ves a tu alrededor" (Trabajadores industriales: GD8).

Estrechamiento del horizonte y escasez de acontecimientos. "Pero a 10 años, yo no soy capaz de ver tan lejos. Porque tanto problema que no me da tiempo a pensar en 10 años. O sea, en 10 meses ya voy apañado. Esa capacidad de mirar... pero es absurdo. No veo que vaya a funcionar como hace 10 años, bajo mi negocio" (Varones autónomos: GD6).

"[Sobre el cambio climático] Eso es para 50 años. Yo quiero comer mañana y ... el año que viene a ver dónde estoy..." (Empleados fijos: GD7).

Bifurcación de dos horizontes de futuro en razón de su extensión o profundidad. "Yo al menos ya no pienso a largo plazo en mí. Pienso, bueno, yo tengo casi mi piso pagado, raro es que no lo termine de pagar, y con poco nos apañaremos... pero pienso en mis hijos, a largo plazo, a corto plazo sí pienso, bueno, a ver si por lo menos no nos quedamos sin trabajo para ir tirando. Pero a largo plazo pienso sobre todo en ellos." (Amas de casa: GD4).

Eje 4 o de las emociones ante el futuro. Se trata de un eje fundamental en el que prima la dimensión emocional. En este eje se contrapone un polo en el que domina la espera tranquila, la realización del deseo, la ilusión mantenida o incluso una fantasía emancipatoria que se sabe tal; frente a esto, en el otro extremo, el miedo y la sensación de desamparo, de no poder confiar en nada a lo que agarrarse y que sea garantía del día de mañana. Entre estas posiciones extremas, se sitúan las posiciones realistas, nada entusiastas, que fijan fríamente lo que cabe esperar y la necesaria acomodación a lo cotidiano.

La esperanza es el soporte de un futuro. En ocasiones es una esperanza compacta y tranquila en la que se une el futuro imaginado y el futuro deseado; la esperanza de quien se sabe situado en un proceso en el que se suceden etapas y al final aparece la luz:

"Dentro de diez años me imagino trabajando en el mismo sitio. Sí. Y espero que con las condiciones laborales mejores, porque ahora se están mermando mucho y esperemos que la crisis haya remitido y volvamos otra vez a retomar el camino. Ese es el deseo que tengo" (Empleados fijos: GD7).

Pero en otros, se trata de un esperanza-refugio, un sentimiento al que acogerse, necesario para vivir. Y así la reflexión sobre la esperanza en este fragmento, alude más a lo que se quiere tener, que a lo que se tiene:

[Moderador] Con relación a esto que han planteado aquí de que la gente no ve futuro... ¿creéis que es así?

[A] "A nivel teórico sí. A nivel práctico todos tenemos esperanzas... porque si no..." 
[B] "Todo el mundo quiere tener la esperanza..." (Funcionarios: GD1).

Una variante significativa es la que envuelve el futuro en la fantasía. Gustaría que tal cosa ocurriera, es más, se presenta como lo más correcto, pero se sabe que se trata de fantasías difíciles de cumplir:

"dices: Pues si me voy al campo y hago una economía de subsistencia de: dos gallinas, un cerdo y plantar tomates. Es que ya llega un momento que dices: O me apeo del sistema... no es que lo vea muy fácil, no, pero ya te pones a pensar y dices: Jo, es que estoy aquí jugando a su juego... el juego que se ha planteado no sé quién..." (Mujeres técnicas: GD2).

A medio camino en la trayectoria hacia el miedo y el desamparo, parece el juego entre el deseo y el temor realista, la contraposición del futuro deseado y el futuro temido:

"Yo veo dos futuros, sinceramente. Uno, que es el que espero, y otro que es el que no espero. O sea, el cielo y el infierno. El que espero... joder, seguir trabajando en la química y haber mejorado. El que no espero, de camarero" (Varones autónomos: GD7).

En el polo extremo, surge la pasión fría del miedo. Está en la mayoría de las intervenciones, sobre todo al comparar el futuro tal como se esperaba (futuro pasado) y el futuro tal como lo vemos ahora (futuro presente):

"Porque la verdad es que futuro... no tiene nada que ver con lo que podíamos pensar hace diez años o quince...o pensaban nuestros padres cuando decidían casarse con veinte años, tenernos con veintidós. Hemos ido para atrás, pero una barbaridad" (Jóvenes temporales: GD9).

Esta sensación de frustración y de ir hacia atrás, se muestra en algún caso como una mezcla cuasi infantil de miedo y desamparo:

"miedo, pero luego que no te amparan instituciones, porque siempre hemos estado amparados por el Estado... Entonces, el miedo, incertidumbre... de repente te dicen los políticos del Estado... que hay esta cifra, y desde Europa te dicen que la cifra no es buena, es pa' la... Entonces dices.... ¿a quién creo? Entonces aparte de miedo, es desamparo" (Mujeres técnicas: GD2).

Eje 5 o de la novedad. Lo que aquí se juega es la espera de un futuro imaginado como sucesión de novedades que, en su forma más radical, no tendrían precedente y conformarían un mundo nuevo (que habrá que imaginar), con independencia de cómo se juzgue (bien o mal), frente a la idea de un futuro en el que, en contra de todas nuestras expectativas, se recupera o restaura algo que ya existía anteriormente y se creía superado o abolido, es decir, un futuro imaginado como una vuelta del pasado cerrando un gran bucle.

Como expresión de la imagen tan arraigada de un futuro de novedades sigue incidiendo la imagen del futuro tecnológico que es la expresión más plena del cambio hacia lo novedoso (una novedad, por decirlo así, colonizada, resultado de la técnica racional). Con todo, no tiene la relevancia que tenía en el discurso del tiempo en épocas anteriores a la crisis. Además de tener menor incidencia, tampoco aparece un discurso nítido de confianza en los valores emancipatorios de las 'nuevas' tecnologías. El maridaje de la hipérbole tecnológica de las TICs y la utopía del futuro ha sido disuelto por la crisis. Considérese en este sentido la siguiente intervención de jóvenes con trabajo temporal:

"[vamos a ser] más tecnológicos, sí... Eso es una cosa que siempre va a más, siempre... no es una cosa que vaya en retroceso. Entonces... cada vez habrá menos cosas físicas y más tecnológicas, más Internet, habrá muchísimas menos cosas de tú a tú, sino que simplemente desde tu casa... yo creo que la gente va a ser menos sociable todavía... porque ya la gente joven cada vez sabe menos tener conversaciones, porque están más que con su WhatsApp, con su móvil... y en eso vamos a retroceder... creo..." (Jóvenes temporales: GD9).

"yo me pongo a pensar y es que, en un futuro, va a ser todo tecnología... Yo en ese aspecto lo veo un poco oscuro también. Tanta tecnología..." (Jóvenes temporales: G9).

Pero las intervenciones más recurrentes no enfatizan la novedad, sino la vuelta del pasado, la restauración futura de algo que se creía superado: el pasado como futuro. Es un tópico que se reitera:

"pasará como antes, que el que no tiene dinero no podrá ni estudiar y se tendrá que buscar la vida, pues un poco de mala manera... pero lo malo de ahora es que pasará como antes" (Trabajadoras: GD5).

"Estamos volviendo a lo de antes, antiguamente, a la tartera y punto. La tartera, las chimeneas... en mi pueblo hacía que no se veía una fogata, mil años... todo calefacción.

Pues ya se están encendiendo. Y en el campo no cortaba una encina nadie... pues ahora se pegan por ella... es así [...]... Estamos volviendo a la edad de antes, vamos a los tiempos de antes" (Varones autónomos: GD6). 


\begin{abstract}
"Como antiguamente... como decía mi padre con los señoritos, dependiendo de los señoritos, o sea, dependiendo de los ricos ricos" (Varones autónomos: GD6).
\end{abstract}

Eje 6 o de la mejora. Es un eje relacionado, pero no identificado, con el anterior. En él se contrapone el tópico moderno de un futuro que supone avance o mejora (inmediatos o a medio/largo plazo) con el tópico emergente que barrunta pérdida o deterioro o asegura que las cosas se mantendrán sin cambios de valor, tal como ahora. Las metáforas recurrentes son dinámicas: avanzar, retroceder, subir, bajar, etc. Lo relevante en todas estas intervenciones es el marco de fondo de la CRISIS. La confianza en que la crisis acabará y habrá una mejora aparece en pocas intervenciones: en unos casos como producto de una deriva, que es la de la sociedad moderna y sus crisis episódicas, y en otros más como deseo o esperanza que como certeza. Son colectivos con una cierta estabilidad o seguridad (propia o del medio familiar) los que más apuestan por esta reafirmación cautelar del futuro de avances y progresos. Alguna intervención basta para mostrarlo:

"[A] yo espero que dentro de diez años podamos estar un poquito mejor que ahora.

[B] Yo creo que estaremos mejor pero diferente, o sea, desde el punto de vista económico y laboral, nunca va a ser lo que ha sido hasta ahora [espero] no quedarme con lo que tengo, sino seguir avanzando" (Mujeres técnicas: GD2).

Pero el tópico recurrente es el que vaticina una deriva hacia peor.

"estamos perdiendo todos los derechos que hemos adquirido a lo largo de los años" (Ama de casa: GD4).

"para atrás [...] yo dentro de cinco años me veo mucho peor que ahora" (Mujer asalariada: GD5).

"Yo soy pesimista, desde luego. Tal y como está el patio soy pesimista. De momento va subiendo todo menos lo que tiene que subir, entonces el poder adquisitivo de todos nosotros, yo creo que nos está devaluando, está bajando. Cosas que hace un tiempo tenías acceso o bien las recortas o bien las suprimes. Entonces yo soy pesimista, porque esto no tiende a ir mejor" (Varones autónomos: GD6: 1).

"Estamos yendo cada vez más para atrás" (Jóvenes temporales: GD9).

Adicionalmente, aflora la esperanza de que el futuro no vaya a peor sino que se mantengan las cosas como hasta ahora, aunque sea en términos de una esperanza muy cargada de deseo que es un tópico recurrente:
"El que sigue currando, yo en mi caso, cuando llega final de año, es que no pienso ni en que me suban el sueldo. Virgencita que me quede como estoy" (Trabajador industria química: G8).

\section{CONCLUSIONES}

El repertorio de sentido a la mano proporciona retazos discursivos que muestran la utilidad de la analítica del futuro que se ha propuesto; conecta además con las discusiones de la tradición de investigaciones sobre el campo y permite afrontar de forma interesante la problemática del futuro. El futuro no puede empezar, decía Niklas Luhmann (1976). No puede hacerlo porque es un horizonte que se manifiesta en múltiples perspectivas en las que suelen contrastarse los futuros pasados (lo que creíamos que iba a ocurrir) con los futuros presentes (lo que creemos que puede ocurrir). Esas perspectivas difieren por su profundidad y demás rasgos que señalara en su momento Joseph Nuttin (1985). Pero también se muestran diferentes en sus dimensiones estratégicas, especialmente en lo que se refiere a lo que conocemos o desconocemos, creemos o no creemos poder hacer, confiamos o tememos. Se ha podido fijar un repertorio-desde luego no definitivo- de esas diferencias. Pero lo más relevante es que entre sus piezas se hace a la luz la problematización del futuro, que podemos describir mejor ahora.

No se trata de una problematización al modo del catastrofismo (preferentemente) posmoderno, que lo hace desaparecer absorbido por un presente voraz. Ni tampoco del futuro patológico al modo de los psicólogos sociales, ya que lo 'anormal' está demasiado 'normalizado' como para poder ser considerado tal. Lo que más bien se muestra es que, sobre el fondo del futuro tópico de la modernidad -que se despliega en profundidad, ya colonizado, sometido a la acción y resuelto a la espera de novedades que supondrán mejoras-, emergen nuevos tópicos extraños a esos sobreentendidos. Aparecen al hilo de la autoconciencia de la CRISIS; no para dinamitar el sentido, sino para proveer nuevas fuentes de sentido. $Y$ aparecen de forma recurrente, aunque ciertamente en variantes y con portadores sociales distintos. Por un lado, la insistencia en la ceguera, en la voluntad de no ver o escuchar, de desentenderse de algo que, sin embargo, se considera que está al acecho. Por otro lado, la conciencia de los límites de la propia capacidad de acción ante algo que viene o sale por sí mismo, hijo más de la fortuna que del propio obrar. Además, la crisis de la confianza y la recurrencia del temor ante lo que pueda 
ocurrir. Por último, la sospecha de que el futuro tal vez no nos depare novedades inusitadas ni mejoras finales, sino que sea una vuelta a lo que felizmente abandonamos o una pérdida que, según el tiempo más se despliega, más se ahonda.

\section{AGRADECIMIENTOS}

Este artículo se enmarca en la investigación Riesgo, incertidumbre y vulnerabilidad en España (CSO201020235), desarrollada junto con Javier Callejo en el marco del Plan Nacional de I+D+i de la Secretaría de
Estado de Investigación, Desarrollo e Innovación del Ministerio de Economía y Competitividad. Agradezco a los profesores Juanma Iranzo e Ignacio Sánchez de la Yncera sus observaciones sobre una primera versión del trabajo. También a las coeditoras de este monográfico, Izaskun Artegui y Matxalen Legarreta, por su exigencia de claridad y rigor. Por último, quiero dar las gracias a los asistentes al Grupo de Trabajo de Sociología del Tiempo, celebrado en Madrid en septiembre de 2013 , en el que se debatió una primera versión de este trabajo.

\section{NOTAS}

1. La referencia completa de la investigación aparece al final del artículo.

2. Entre noviembre de 2012 y mayo de 2013 se desarrolló la primera fase del trabajo de campo; se realizaron entonces nueve grupos de discusión (GD) en Madrid, Toledo, Valladolid y Tarragona. La ficha muy sintética de los grupos es: GD1: Funcionarios. Varones; GD2: Técnicos y profesionales. Mujeres; GD3: Estudiantes universitarios. Mixto; GD4: Amas de casa; GD5: Trabajadoras asalariadas; GD6: Autónomos. Varones; GD7: Empleados fijos en el sector tecno-industrial. Mixto; GD8: Trabajadores industriales. Varones; GD9: Jóvenes con trabajo temporal. Mixto. La investigación está conectada con trabajos ya publicados: véase Ramos Torre (1999 y 2002a).

3. La semántica social de la crisis será analizada en un estudio ya en curso. Sobre el concepto moderno de crisis véase el trabajo clásico de Koselleck (2007, pp. 241 y ss.).

4. Véanse su seminal libro escrito en colaboración con Mau (Bell y Mau, 1971) y sus escritos posteriores, especialmente Bell (2009).

5. Véase el monográfico no 43 de la revista Futures (2011) dedicado a Wendell Bell y la escuela de estudios futurológicos. Se pueden encontrar dos evaluaciones enfrentadas del movi- miento en Masini (1998) y en Marien (1987 y 2011).

6. Véase especialmente la apreciación crítica de conjunto de Barbara Adam (2011).

7. Para una visión de conjunto véase Strathman y Joireman (2005).

8. Como muestra de este tipo de investigaciones cabe señalar un conjunto de trabajos sobre la imagen y vivencia del futuro de jóvenes norteuropeos: arrancan de una discusión del trabajo pionero de Nilsen (1999) cuya tesis, en seguimiento de Helga Nowotny, sobre la sustitución del futuro propiamente dicho a favor de un presente extendido, corroboran, matizan, complejizan o rechazan. Véanse Brannen y Nilsen (2002); Devadason (2008); Anderson, Bechhofer, McCrone, Jamieson, Li y Stewart (2005).

9. En este sentido, hay que distinguir perspectivas tan dispares como la celebrativa de Lipovesky, la constatativa de Castells o la fuertemente crítica de Baumann y sobre todo Innerarity, de entre los autores citados.

10. Sobre la tendencia a la temporalización y presentificación de la realidad, relevante en la sociología de las últimas décadas y sus conexiones con la desaparición del futuro, véase Ramos Torre (2014) y la amplia información bibliográfica ahí recogida.
11. Luhmann se apoya en Koselleck (1985), así como en las propuestas de los años 30 de Lovejoy (1983) sobre la temporalización moderna de la gran cadena del ser.

12. Aunque con alguna reticencia al considerarlo responsable de la línea de investigación que separa totalmente los futura y los facta (véase Adam y Groves, 2007, p. 172).

13. Para marcar visualmente la diferencia, el término en redonda es el sustantivo; la cursiva indica el adjetivo.

14. Sobre la metáfora del tiempo como horizonte y otras metáforas sociales del tiempo ver Ramos (2007).

15. La diferencia hacer/sufrir la propone Arendt para dar cuenta de las dos caras de la acción humana: agencia y paciencia (Arendt, 1993).

16. Propone Wittgestein (1988, p. 44c): “Proposición 341.Las preguntas que hacemos y nuestras dudas descansan sobre el hecho de que algunas proposiciones están fuera de duda, son -por decirlo de algún modo- los ejes sobre los que giran aquéllas"; "Proposición 343. Pero no se trata de que no podamos investigarlo todo y que, por lo mismo, nos debamos conformar forzosamente con la suposición. Si quiero que la puerta se abra, los goznes deben mantenerse firmes". 


\section{BIBLIOGRAFÍA}

Adam, B. E. (2011). Wendell Bell and the sociology of the future: Challenges past, present and future. Futures, 43, 6, pp. 590-595. https://doi.org/10.1016/j.futures.2011.04.007

Adam, B. y Groves, C. (2007). Future Matters: Action, Knowledge, Ethics. Leiden: Brill. https://doi.org/10.1163/ ej.9789004161771.i-218

Anderson, M., Bechhofer, F., McCrone, D., Jamieson, L., Li, Y. y Stewart, R. (2005). Timespans and Plans Among Young Adults. Sociology, 39, 1, pp. 139-155. https://doi. org/10.1177/0038038505049006

Arendt, H. (1993). La condición humana. Barcelona: Paidos.

Baldwin, P. (1992). La política de solidaridad social. Bases sociales del estado de bienestar europeo, 1875-1975. Madrid: Ministerios de Trabajo y Seguridad Social.

Bauman, Z. (2000). Liquid Modernity. Cambridge: Polity Press.

Bauman, Z. (2007). Tiempos líquidos. Vivir en una época de incertidumbre. Barcelona: Tusquets.

Beck, U. (2008). La sociedad del riesgo mundial. Paidós: Barcelona.

Bell, W. (2009). Foundations of Future Studies: Values, Objectivity and the Good Society. New Brunswick: Transaction Publishers.

Bell, W. y Mau, J. A. (eds.) (1971). The Sociology of the Future. Theory, Cases and Annotated Bibliography. New York: Russell Sage Foundation.

Benjamin, W. (1940/2012). Sobre el concepto de Historia. En Benjamin, W. Obra completa. Madrid: Abada. Libro I, vol. 2, pp. 305-318.

Beriain, J. (2008). Aceleración y tiranía del presente. Barcelona: Anthropos.

Brannen, J. y Nilsen A. (2002). Young People's Time Perspectives: From Youth to Adulthood.Sociology, 36,3, pp513-537.https:// doi.org/10.1177/0038038502036003002

Brown, N., Rappert, B. y Webster, A. (eds.) (2000). Contested Futures. A Sociology of Prospective Techno-Science. Aldershot: Ashgate Publishing.

Castel, R. (1997). La metamorfosis de la cuestión social. Una crónica del salariado. Barcelona: Paidós.
Castells, M. (1997) La era de la información: economía, sociedad y cultura (volumen I. La sociedad red). Madrid: Alianza.

Devadason, R. (2008). To Plan or Not to Plan? Young Adult Future Orientations in Two European Cities. Sociology, 42 pp. 1127-1145. https://doi. org/10.1177/0038038508096937

Douglas, M. (1994). Risk and Blame. London: Routledge.

Eriksen, T. H. (2001). Tyranny of the Moment. Fast and Slow Time in the Information Age. London: Pluto Press.

Ewald, F. (1996). Histoire de l'État providence. Paris: Grasset.

Fischhoff, B. y Kadvany, J. (2013). Riesgo: una breve introducción. Madrid: Alianza.

Innerarity, D. (2009). El futuro y sus enemigos. Barcelona: Paidós

Jameson, F. (1995). El posmodernismo o la lógica cultural del capitalismo. Barcelona: Paidós.

Jameson, F. (2003). The End of Temporality. Critical Inquiry, 29, 4, pp. 695-718. https://doi.org/10.1086/377726

Jouvenel, B. de (1966). El arte de prever el futuro político. Madrid: Rialp.

Kastembaum, R. (1961). The dimensions of future time perspective. An experimental analysis. Journal of General Psychology, 65, pp. 203-218. https://doi.org/10 .1080/00221309.1961.9920473

Koselleck, R. (1985). Futures Past. On the Semantics of Historical Time. Cambridge, Mass.: MIT Press.

Koselleck, R. (2007). Crítica y crisis. Un estudio sobre la patogénesis del mundo burgués. Madrid: Trotta.

Lakoff, G. y Johnson, M. (1995). Metáforas de la vida cotidiana. Madrid: Cátedra.

Leshan, L. L. (1952). Time orientation and social class. Journal of Abnormal and Social Psychology, 47, 3, pp. 589-592. https://doi.org/10.1037/h0056306

Lipovetsky, G. (1986). La era del vacío. Ensayos sobre el individualismo contemporáneo. Barcelona: Anagrama.

Lipovetsky, G. (1990). El imperio de lo efimero. La moda y su destino en las sociedades modernas. Barcelona: Anagrama.

Lovejoy, A. O. (1983). La gran cadena del ser. Historia de una idea. Barcelona: Icaria.
Luhmann, N. (1976). The Future Cannot Begin: Temporal Structures in Modern Society. Social Research, 43, 1, pp. 130-152.

Luhmann, N. (1992). Sociología del riesgo. Guadalajara: Universidad Iberoamericana y Universidad de Guadalajara.

Lyng, S. (ed.). (2005). Edgework: The Sociology of Risk-taking. New York: Routledge.

Marien, M. (1987). What is the nature of our embryonic enterprise? An open letter to Wendell Bell. Futures Research Quarterly, 3, 4, pp. 71-87.

Marien, M. (2011). My differences with Wendell Bell. Futures, 43, pp. 449-456.

Masini, E. B. (1998). Futures Studies from the Experience of a Sociologist Who Tries to Be a Futurist. American Behavioral Scientist, 42, pp. 340-346. https://doi. org/10.1177/0002764298042003005

Mead, G. H. (2008). La filosofía del presente. Madrid: CIS.

Mercure, D. (1983). Typologie des représentations de l'avenir. Loisir et Société, 6, pp. 375-402. https://doi.org/10.1080 /07053436.1983.10715160

Nilsen, A. (1999) Where is the future? Time and space as categories in analyses of young people's images of the future. Innovation, 12, 2, pp. 175-194. https://doi.org/10.1080/13511610.19 99.9968596

Nisbet, R. (1981). Historia de la idea de progreso. Barcelona: Gedisa.

Nuttin, J. (1985). Future time perspective and motivation. Leuven: Leuven University Press.

O'Malley, P. (2004). Risk, uncertainty and government. London: Glasshouse Press.

Ramos Torre, R. (comp.) (1992). Tiempo y sociedad, Madrid: CIS, pp. 161-182.

Ramos Torre, R. (1999). Prometeo y las flores del mal: el problema del riesgo en la sociología contemporánea. En Ramos Torre, R. y García Selgas, F. (eds.) Globalización, riesgo, reflexividad. Tres temas de la teoría social contemporánea. Madrid: CIS, pp. 249-274.

Ramos Torre, R. (2002a). El retorno de Casandra: modernización ecológica, precaución e incertidumbre. En García Blanco, J. M. y Navarro Sustaeta, P. (eds.) ¿Más allá de la modernidad? Las dimensiones de la información, la 
comunicación y las nuevas tecnologías. Madrid: CIS, pp. 403-455.

Ramos Torre, R. (2002b). Sobre los orígenes del principio consecuencial: Leibniz, Mandeville y Vico. En Iglesias de Ussel, J. (coord.) La sociedad: teoría e investigación empírica. Estudios en homenaje a José Jiménez Blanco. Madrid: CIS, pp. 1013-1025.

Ramos Torre, R. (2007). Metáforas sociales del tiempo en España: una investigación empírica. En Prieto, C. (ed.) Trabajo, género y tiempo social. Madrid: Editorial Complutense y Editorial Hacer, pp. 173-204.

Ramos Torre, R. (2014). Atemporalización y presentificación del mundo social en la sociología contemporánea. Política y Sociedad, 51, 1, pp. 147-176. https:// doi.org/10.5209/rev_poso.2014.v51. n1.42409

Rescher, N. (1998). Predicting the Future: An Introduction to the Theory of Forecasting. Albany, NY: SUNY Press.

Rosa, H. y Scheuerman, W. E. (eds.) (2009). High-Speed Society: Social Acceleration, Power and Modernity. Pennsylvania: Pennsylvania State University.

San Agustín (1984). Confesiones. Barcelona: Bruguera.

Strathman A. y Joireman, J. (eds.) (2005). Understanding behavior in the context of time: Theory, research and application. Mahwah, NJ: Erlbaum.

Trommsdorff, G. y Lamm, H. (1975) An analysis of future orientation and some of its social determinants. En Fraser J. T. y Lawrence, N. (eds.) The study of time II. Heidelberg, New York: Springer, pp. 343-361. https://doi.org/10.1007/9783-642-50121-0_26

Valdés Villanueva, L. (ed.) (2012). Aristóteles. Categorías. De interpretatione. Madrid: Tecnos.

Wittgenstein, L. (1988). Sobre la certeza. Barcelona: Gedisa.

Zalesky, Z. (2005). Future orientation and anxiety. En Strathman A. y Joireman, J. (eds.) Understanding behavior in the context of time: Theory, research, and application. Mahwah, NJ: Erlbaum, pp. 125-141.

Zimbardo, P. y Boyd, J. (2009). La paradoja del tiempo. Barcelona: Paidós. 